This item was submitted to Loughborough's Research Repository by the author.

Items in Figshare are protected by copyright, with all rights reserved, unless otherwise indicated.

\title{
Finance and growth in Africa: the broken link
}

PLEASE CITE THE PUBLISHED VERSION

http://dx.doi.org/10.1016/j.econlet.2011.08.007

\section{PUBLISHER}

(c) Elsevier B.V.

\section{VERSION}

AM (Accepted Manuscript)

LICENCE

CC BY-NC-ND 4.0

\section{REPOSITORY RECORD}

Demetriades, Panicos, and Gregory James. 2019. "Finance and Growth in Africa: The Broken Link". figshare. https://hdl.handle.net/2134/15333. 
This item was submitted to Loughborough's Institutional Repository (https://dspace.lboro.ac.uk/) by the author and is made available under the following Creative Commons Licence conditions.

\section{creative
commons}

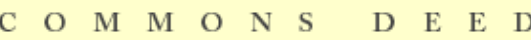

Attribution-NonCommercial-NoDerivs 2.5

You are free:

- to copy, distribute, display, and perform the work

Under the following conditions:

Attribution. You must attribute the work in the manner specified b the author or licensor.

Noncommercial. You may not use this work for commercial purposes.

No Derivative Works. You may not alter, transform, or build upon this work.

- For any reuse or distribution, you must make clear to others the license terms of this work.

- Any of these conditions can be waived if you get permission from the copyright holder.

Your fair use and other rights are in no way affected by the above.

This is a human-readable summary of the Leqal Code (the full license).

\section{Disclaimer 만}

For the full text of this licence, please go to: http://creativecommons.org/licenses/by-nc-nd/2.5/ 


\title{
FINANCE AND GROWTH IN AFRICA: THE BROKEN LINK
}

\author{
Panicos O. Demetriades ${ }^{a}$ and Gregory A. James ${ }^{b}$
}

February 28, 2011

\begin{abstract}
Utilizing the latest panel cointegration methods we provide new empirical evidence from 18 countries that suggests that the link between finance and growth in SubSaharan Africa is 'broken'. Specifically, our findings show that banking system development in this region follows economic growth. They also indicate that there is no link between bank credit and economic growth.
\end{abstract}

KEYWORDS: Panel cointegration, cross-sectional dependence, African financial under-development, African credit markets

$J E L: \mathrm{G} 21,016$

${ }^{a}$ Department of Economics, University of Leicester, University Road, Leicester, LE1 7RH, UK. Email:pd28@1e.ac.uk.

b Corresponding author. Address for correspondence: Department of Economics, School of Business and Economics, Loughborough University, Leicestershire LE11 3TU, UK. Email: G.A.James@lboro.ac.uk. Tel: + 44 (0) 1509 222706. Fax: + 44 (0) 1509223910. 


\section{Introduction}

Although banking systems in Sub-Saharan Africa (SSA) lack depth compared to other parts of the developing world, an influential study by the World Bank has shown that savings mobilization in this region does not represent a binding constraint on financial deepening (Honohan and Beck, 2007). Drawing on surveys and other qualitative information, the World Bank study concludes that SSA banks do not lend enough - and as a result are excessively liquid compared to banks in other regions - because of a lack of acceptable or 'bankable' loan applications. Moreover, the study suggests that bank lending is often unprofitable because of severe information problems including lack of credit bureaus and weak contract enforcement. These intriguing insights lend themselves to rigorous macro-econometric analysis, not least because of their important policy implications. ${ }^{1}$ To this end, this paper provides new macro-econometric evidence from a panel of 18 SSA countries over the period 1975 to 2006 that is consistent with the findings of the World Bank study. Specifically, we provide evidence to suggest that the relationship between finance and growth in the region is a rather loose one: finance, at best, follows growth; at worst there is no evidence of a significant long run link between the two. We show that the worst-case scenario is obtained when financial development is measured by bank credit while the best-case scenario occurs when it is measured by liquid liabilities, an indicator that measures the size of bank balance sheets. ${ }^{2}$

We utilize the latest panel econometric techniques for non-stationary data that make the most of limited data availability for SSA countries. Such data scarcity is indeed the main factor explaining why empirical studies of the finance-growth nexus in Africa are still in their infancy. Although a handful of such studies is now available - a good example of which is Gries et al. (2009) - these studies rely on individual country estimates obtained with relatively small samples and, as such, inference may be unreliable and/or inefficient compared to panel data methods. In contrast, the techniques we utilize circumvent these problems by combining 32 time observations with 18 cross-sections, resulting in a sample of 576 observations. This generates marked improvements in the reliability of statistical inference while respecting the non-stationary properties of the data and allowing cross-country heterogeneity. We avoid the limitations of conventional panel cointegration methods by allowing for cross-country dependence, utilizing some of the very latest advances in the panel cointegration literature.

The rest of the paper is organized as follows. Section 2 outlines the data and econometric methodology. Section 3 presents and discusses the empirical results. Section 4 summarizes and concludes.

\footnotetext{
1 These ideas are developed further in a recent paper by Andrianova et al. (2010), which shows that, when contract enforcement is weak, a credit market equilibrium with a high degree of loan defaults and low bank lending - the 'African credit trap' - can arise. Andrianova et al. (2010) also provide micro-econometric evidence utilizing panel data on hundreds of African banks over a tenyear period that is consistent with these predictions.

2 This is what would be expected if banks do not lend 'enough'. In such circumstances, financial development, if measured by indicators that proxy the demand for financial services, could still exhibit a stable relationship with economic growth, although it would follow growth generated elsewhere. However, financial deepening, regardless of how it is measured, is unlikely to result in additional growth if it does not lead to an expansion in bank credit.
} 


\section{Data and Methodology}

The basic empirical model we postulate between financial and economic development, denoted $F D_{i t}$ and $Y_{i t}$ respectively, is the following simple log-linear relationship

$$
\ln \left(F D_{\mathrm{it}}\right)=\mu_{\mathrm{i}}+\beta_{\mathrm{i}} \ln \left(Y_{\mathrm{it}}\right)+e_{\mathrm{it}}
$$

where the index $i=1, \ldots, N$ denotes countries and $t$ denotes time.

We use a panel of 18 SSA countries that covers the period 1975-2006. ${ }^{3}$ Annual data for financial development is obtained from the Financial Development and Structure Database of Beck et al. (2001), updated in April 2010. Specifically, we extract bank deposits to GDP (BD), liquid liabilities to GDP (LL) and private credit by deposit money banks to GDP (PC), each transformed in logarithms. Economic development is measured by real GDP per capita in international dollars (2005 constant prices), labeled LY, also transformed in logarithms, and is obtained from the PENN World Table (Table 6.3), compiled by Heston et al. (2006), updated in November 2009.

To test whether the variables are stationary or not, we consider five panel unit root tests. The first group consists of the tests of Im et al. (2003), Levin et al. (2002) and Harris and Tzavalis (1999), denoted $W_{t b a r}, t^{*}$ and $\rho$, respectively, which assume cross-sectional independence. The second group of tests allows for crosssectional dependence and comprises the tests of Breitung (2000) and Pesaran (2007), denoted $\lambda$ and $Z_{t b a r}$, respectively. ${ }^{4}$ All tests are normally distributed under the common null hypothesis of non-stationarity.

Provided that the variables are I(1) and that the regression error is stationary, equation (1) may be viewed as representing a cointegrating relationship. The second step in our analysis is, therefore, to test whether financial and economic development are cointegrated. We use the four panel cointegration tests of Westerlund (2007), which have good small-sample properties and high power relative to popular residual-based panel cointegration tests (e.g. Pedroni, 2004). Furthermore, asymptotic and bootstrap $p$-values are computed, the latter making inference possible under very general forms of cross-sectional dependence. The tests are designed to test the null hypothesis of no cointegration by testing whether the error correction term in a conditional error correction model is equal to zero. If the null hypothesis of no error correction is rejected, then the null hypothesis of no cointegration is also rejected. The error correction model we consider is as follows:

$\Delta \ln \left(F D_{\mathrm{itt}}\right)=\alpha_{\mathrm{i}}+\rho_{\mathrm{i}}\left(\ln \left(F D_{\mathrm{it}-1}\right)-\beta_{\mathrm{i}} \ln \left(Y_{\mathrm{it}-1}\right)\right)+\sum\left(s=1, \ldots, p_{\mathrm{i}}\right) \delta_{\mathrm{is}} \Delta \ln \left(F D_{\mathrm{it}-\mathrm{s}}\right)+\sum\left(s=0, . ., p_{\mathrm{i}}\right) \lambda_{\mathrm{is}} \Delta \ln \left(Y_{\mathrm{it}-\mathrm{s}}\right)+e_{\mathrm{it}}(2)$

\footnotetext{
3 The countries are: Burundi, Burkina Faso, Côte d'Ivoire, Cameroon, Ethiopia, Gabon, Ghana, Gambia, Kenya, Madagascar, Mauritius, Niger, Nigeria, Senegal, Sierra Leone, Swaziland, Seychelles and Togo. These countries were chosen taking into account data availability and the fact that the techniques employed in this paper require a balanced panel. We have tried to include as many countries as possible over as long a sample period as possible.

${ }^{4}$ We consider a variant of the Breitung (2000) test made robust to cross-sectional dependence.
} 
To formally test whether the cross-sectional units are independent, we assume that $e_{i t}$ is formed by a combination of a fixed component specific to the country and a random component that captures pure noise and estimate (2) using the FE estimator. We then use the Pesaran (2004) CD test on the residuals of (2) under the FE specification. The CD test statistic is normally distributed under the null hypothesis of no cross-sectional dependence.

Finally, where evidence of cointegration is obtained, the third step in our analysis consists in estimating the long-run coefficient of real income per capita (LY). For this purpose, we use the newly developed estimators of Bai et al. (2009) known as CupBC (continuously-updated and bias-corrected) and CupFM (continuously updated and fully-modified) estimators. These two estimators have been shown to be superior in terms of mean bias to the LSDV (least squares dummy variables) and 2sFM (2-stage fully modified) estimators.

\section{Empirical Results}

The results of the panel unit root tests reported in Table 1 suggest that the unit root null hypothesis cannot be rejected at any conventional significance level for any variables. ${ }^{5}$ The only exception is LL, for which the null can be rejected at the $10 \%$ level when using the $W_{\text {tbar }}$ test. Since this rejection is very marginal, we treat all four variables as non-stationary and proceed to test for cointegration.

The computed values of the panel cointegration statistics are presented in Table 2 along with the asymptotic and bootstrapped $p$-values based on 500 replications. ${ }^{6}$

The results from equation (2) with bank deposits as the dependent variable indicate that the no cointegration null is never rejected when using the asymptotic $p$-values, except for $G_{\tau}$ at the $10 \%$ level (i.e. when $\rho_{i}$ is not restricted to be homogenous). Based on the bootstrapped $p$-values (i.e. when allowance is made for cross-sectional dependence), the no cointegration null is only rejected for $G_{r}$ at the $5 \%$ level. Hence, there is little evidence of cointegration in this case. Similarly, the results with private credit as the dependent variable show that the no cointegration null is never rejected, providing even less support for cointegration.

In contrast, the results with liquid liabilities as the dependent variable provide evidence of cointegration. With the asymptotic $p$-values, the no cointegration null is not only rejected for $G_{\tau}$ at the $1 \%$ level but also for $P_{\tau}$ at the $10 \%$ level (i.e. when $\rho_{i}$ is restricted to be homogenous), suggesting that the whole panel is cointegrated. The results with the bootstrapped $p$-values provide even stronger evidence of cointegration. The no cointegration null is always rejected at least at the $10 \%$ level regardless of whether $\rho_{i}$ is restricted to be homogenous or not. Since the homogenous alternative is particularly restrictive, these results provide strong evidence that the whole panel is cointegrated.

\footnotetext{
5 The Pesaran (2007) test is performed using the Stata "pescadf" command written by Piotr Lewandoski.

6 The tests are performed using the Stata "xtwest" command (see Persyn and Westerlund, 2008). In small datasets, as in this study with $T=32$, Westerlund (2007) warns that the results of the tests may be sensitive to the specific choice of lag and lead lengths. Hence, to avoid overparametrization and the resulting loss of power, we hold the short-run dynamics fixed (i.e. $p_{i}=p=1$ ) in equation (2).
} 
The Westerlund (2007) tests rely on the assumption of weakly exogenous regressors. In order to shed some light on the appropriateness of this assumption, we perform a series of reverse regression tests, the results of which are reported in Table 3. If LY is indeed weakly exogenous, then it should not be errorcorrecting. The results with LY as the dependent variable show that, consistent with the notion of weak exogeneity, the null of no error-correction cannot be rejected with either of the finance indicators as the regressor. Hence, there seems to be no violation of the weak exogeneity assumption.

The results of the cross-sectional independence tests are reported in Table $4 .^{7}$ The CD test always strongly rejects the null hypothesis of no cross-sectional dependence.

Since we find evidence of cointegration between liquid liabilities and real GDP per capita, we proceed to estimate the long-run coefficient of LY with LL as the dependent variable. We use the Bai et al. (2009) estimators in order to account for the cross-sectional dependence in the data. The CupBC and CupFM estimation results are reported in Table $5 .{ }^{8}$ Both estimators produce very similar results. The estimated coefficient is positive and significant in both cases. This suggests the existence of a stable and positive long-run relationship between the ratio of liquid liabilities to GDP and economic development. Furthermore, the magnitude of the estimated coefficient suggests that a $1 \%$ increase in real per capita income translates on average into a $2 \%$ increase in banking system development.

\section{Summary and Policy Implications}

The empirical results lead to the following three key findings relating to the relationship between finance and growth in Sub-Saharan Africa:

(i) Banking system development as measured by liquid liabilities is positively associated to real GDP per capita. In other words, richer countries in SubSaharan Africa will tend to have more developed banking systems.

(ii) Bank credit does not exhibit a long run relationship with real GDP per capita. In light of finding (i), this suggests that while banking systems may grow in tandem with economic growth, their ability to extend credit to the private sector does not follow suit.

(iii) Real income per capita is weakly exogenous with respect to financial development, however measured. Loosely speaking, finance does not lead to economic growth in SSA.

These findings, which are consistent with the insights of Honohan and Beck (2007), Andrianova et al. (2010) and Demetriades and Fielding (2010), highlight the dysfunctional nature of African credit markets. Banking systems could be growing reflecting increased demand for financial services, while vital firm and household credit remains scarce. The broken link between the real economy and bank credit can go some way in explaining why financial development does not result in additional economic growth. Fixing this link seems essential to kick start the finance and growth cycle in Sub-Saharan Africa. To this end, the strengthening of creditor protection laws and related informational infrastructure, including credit information bureaus, seems critical.

\footnotetext{
7 The test is performed using the Stata "xtcsd" command (see De Hoyos and Sarafidis, 2006).

8 The estimations are conducted using GAUSS programming.
} 


\section{Acknowledgements}

We acknowledge financial support from the ESRC (Award reference RES-00022-2774). We would like to thank Badi Baltagi, Mauro Costantini, George Anayiotos and participants at the MMFRG workshop on African Credit Markets at the Bank of England for their helpful comments. The usual disclaimer applies.

\section{References}

Andrianova, S., Baltagi, B., Demetriades, P. and Fielding, D. (2010). The African credit trap. Discussion Papers in Economics 10/18, Department of Economics, University of Leicester, revised Oct 2010.

Bai, J. Kao, C. and Ng, S. (2009). Panel cointegration with global stochastic trends. Journal of Econometrics, 149, pp. 82-99.

Bai, J. and Ng, S. (2004). A panic attack on unit roots and cointegration. Econometrica, 72, pp. 1127-1177.

Beck, T., Demirgüc-Kunt, A. and Levine, R. (2001). A new database on financial development and structure. World Bank Economic Review, 14, pp. 597-605.

Breitung, J. (2000). The local power of some unit root tests for panel data, in B. Baltagi (ed.) Nonstationary Panels, Panel Cointegration, and Dynamic Panels, Advances in Econometrics, Vol. 15. JAI: Amsterdam.

De Hoyos, R.E. and Sarafidis, V. (2006). Testing for cross-sectional dependence in panel-data models. The Stata Journal, 6, pp. 482-496.

Demetriades, P.O. and Fielding, D. (2010). Information, institutions and banking sector development in West Africa. Economic Inquiry, forthcoming.

Gries, T., Kraft, M. and Meierrieks, D. (2009). Linkages between financial deepening, trade openness, and economic development: causality evidence from Sub-Saharan Africa. World Development, 37, pp. 1849-1860.

Harris, R.D.F. and Tzavalis, E. (1999). Inference for unit roots in dynamic panels where the time dimension is fixed. Journal of Econometrics, 91, pp. 201-226.

Heston, A., Summers, R. and Aten, B. (2006). Penn World Table Version 6.2, income and prices at the University of Pennsylvania. Center for International Comparisons of Production.

Honohan, P. and Beck, T. (2007). Making finance work for Africa. The International Bank for Reconstruction and Development/The World Bank.

Im, K.S., Pesaran, M.H. and Shin, Y. (2003). Testing for unit roots in heterogeneous panels. Journal of Econometrics, 115, pp. 53-74. 
Levin, A., Lin, C.-F. and Chu, C.-S. (2002). Unit root tests in panel data: asymptotic and finite-sample properties. Journal of Econometrics, 108, pp. 1-24.

Newey, W. and West, K. (1994). Autocovariance lag selection in covariance matrix estimation. Review of Economic Studies, 61, pp. 631-653.

Pedroni, P.L. (2004). Panel cointegration: asymptotic and finite sample properties of pooled time series tests with an application to the purchasing power parity hypothesis. Econometric Theory, 20, pp. 597- 625.

Persyn, D. and Westerlund, J. (2008). Error-correction-based cointegration tests for panel data. The Stata Journal, 8, pp. 232-241.

Pesaran, M.H. (2004). General diagnostic tests for cross section dependence in panels. CESifo Working Papers, No. 1229.

Pesaran, M.H. (2007). A simple panel unit root test in the presence of cross section dependence. Journal of Applied Econometrics, 22, pp. 265-312.

Westerlund, J. (2007). Testing for error correction in panel data. Oxford Bulletin of Economics and Statistics, 69, pp. 709-748. 
TABLE 1: Unit Root Tests

\begin{tabular}{|c|c|c|c|c|c|c|c|c|c|c|}
\hline \multirow[b]{2}{*}{ Variable } & \multicolumn{4}{|c|}{ Test values } & \multirow[b]{2}{*}{$\overline{Z_{\text {tbar }}}$} & \multicolumn{5}{|c|}{$p$-values } \\
\hline & $\overline{W_{t b a r}}$ & $t^{*}$ & $\rho$ & $\bar{\lambda}$ & & $W_{\text {tbar }}$ & $t^{*}$ & $\bar{\rho}$ & $\bar{\lambda}$ & $\overline{Z_{t b a r}}$ \\
\hline$\overline{\mathrm{BD}}$ & -0.134 & 0.742 & 0.820 & 0.312 & 1.273 & 0.446 & 0.771 & 0.893 & 0.622 & 0.899 \\
\hline LL & -1.574 & -1.201 & 0.792 & 0.170 & -0.933 & 0.057 & 0.114 & 0.652 & 0.567 & 0.175 \\
\hline PC & -0.646 & -1.238 & 0.863 & 1.378 & 2.093 & 0.259 & 0.107 & 0.994 & 0.916 & 0.982 \\
\hline LY & 0.352 & 1.082 & 0.819 & 0.955 & 0.927 & 0.637 & 0.860 & 0.883 & 0.830 & 0.823 \\
\hline
\end{tabular}

Notes: All unit-root tests are implemented with a constant and trend in the test regression and take a unit-root as the null hypothesis. For semi-parametric corrections, the Bartlett kernel is employed with the Newey and West (1994) bandwidth selection algorithm. All bandwidth and lag orders are set according to the rule $4(T / 100)^{2 / 9}$. The lags are chosen according to the Akaike criterion. The $p$-values are for a one-sided test based on the normal distribution. 
TABLE 2: Cointegration Tests

\begin{tabular}{|c|c|c|c|c|c|c|c|c|c|}
\hline \multirow[b]{2}{*}{ Test } & \multicolumn{3}{|c|}{$\overline{\mathrm{BD}}$} & \multicolumn{3}{|c|}{$\overline{\mathrm{LL}}$} & \multicolumn{3}{|c|}{$\overline{\mathrm{PC}}$} \\
\hline & $\overline{\text { Value }}$ & $p$-val $^{\mathrm{a}}$ & $p$-val $^{\mathrm{b}}$ & $\begin{array}{l}\text { Value } \\
\text {. }\end{array}$ & $\overline{p-\mathrm{val}^{a}}$ & $p$-val ${ }^{b}$ & Value & $p$-val ${ }^{\mathrm{a}}$ & $p$-val $^{\mathrm{b}}$ \\
\hline$\overline{G_{r}}$ & -2.100 & 0.064 & 0.042 & -2.289 & 0.008 & 0.004 & -1.682 & 0.675 & 0.400 \\
\hline$G_{a}$ & -6.704 & 0.634 & 0.146 & -7.741 & 0.320 & 0.026 & -5.226 & 0.928 & 0.460 \\
\hline$P_{r}$ & -6.744 & 0.272 & 0.262 & -7.633 & 0.067 & 0.080 & -5.306 & 0.800 & 0.540 \\
\hline$P_{a}$ & -4.316 & 0.467 & 0.282 & -5.244 & 0.166 & 0.096 & -3.617 & 0.721 & 0.364 \\
\hline
\end{tabular}

Notes: The Westerlund (2007) tests take no cointegration as the null. The test regression is fitted with a constant and one lag and lead. The kernel bandwidth is set according to the rule $4(T / 100)^{2 / 9}$. ${ }^{\text {a The }} p$-values are for a one-sided test based on the normal distribution. ${ }^{b}$ The $p$-values are for a one-sided test based on 500 bootstrap replications. 
TABLE 3: Weak Exogeneity Tests

\begin{tabular}{|c|c|c|c|c|c|c|c|c|c|}
\hline \multirow{2}{*}{$\begin{array}{c}\text { LY } \\
\text { (dependent) } \\
\text { Test }\end{array}$} & \multicolumn{3}{|c|}{$\mathrm{BD}$ (regressor) } & \multicolumn{3}{|c|}{ LL (regressor) } & \multicolumn{3}{|c|}{ PC (regressor) } \\
\hline & Value & $p$-val ${ }^{\mathrm{a}}$ & $p$-val ${ }^{\mathrm{b}}$ & Value & $p$-val ${ }^{a}$ & $p$-val $^{b}$ & Value & $p$-val ${ }^{\mathrm{a}}$ & $p$-val ${ }^{\mathrm{b}}$ \\
\hline$\overline{G_{r}}$ & -1.821 & 0.418 & 0.278 & -1.794 & 0.470 & 0.312 & -1.876 & 0.332 & 0.208 \\
\hline$G_{a}$ & -6.458 & 0.703 & 0.264 & -5.837 & 0.845 & 0.418 & -6.069 & 0.798 & 0.380 \\
\hline$P_{r}$ & -7.228 & 0.124 & 0.210 & -7.362 & 0.110 & 0.146 & -7.159 & 0.153 & 0.206 \\
\hline$P_{a}$ & -4.956 & 0.244 & 0.212 & -4.915 & 0.256 & 0.176 & -4.591 & 0.365 & 0.244 \\
\hline
\end{tabular}

Notes: The Westerlund (2007) tests are implemented with LY as the dependent variable. The test regression is fitted with a constant and one lag and lead. The kernel bandwidth is set according to the rule $4(T / 100)^{2 / 9}$. ${ }^{a}$ The $p$-values are for a one-sided test based on the normal distribution. ${ }^{b}$ The $p$-values are for a one-sided test based on 500 bootstrap replications. 
TABLE 4: Cross-Sectional Independence Tests

\begin{tabular}{|c|c|c|c|c|c|c|c|c|c|}
\hline \multirow[b]{2}{*}{ Test } & \multicolumn{3}{|c|}{$\overline{\mathrm{BD}}$} & \multicolumn{3}{|c|}{$\overline{\mathrm{LL}}$} & \multicolumn{3}{|c|}{$\overline{\mathrm{PC}}$} \\
\hline & Value & $p$-value & Correlation & Value & $p$-value & Correlation & Value & $p$-value & Correlation \\
\hline$C D$ & 4.880 & 0.000 & 0.166 & 4.901 & 0.000 & 0.163 & 4.858 & 0.000 & 0.163 \\
\hline
\end{tabular}

Notes: The Pesaran (2004) $C D$ test takes cross-sectional independence as the null. The $p$-values are for a one-sided test based on the normal distribution. Correlation is the average absolute value of the off-diagonal elements of the cross-sectional correlation matrix of residuals obtained from estimating (2) under an FE specification. 
TABLE 5: Cointegration Estimation Results

\begin{tabular}{|c|c|c|c|}
\hline \multicolumn{2}{|c|}{ CupBC } & \multicolumn{2}{|c|}{ CupFM } \\
\hline $\bar{\beta}$ & $\overline{\mathrm{SE}}$ & $\bar{\beta}$ & $\overline{\mathrm{SE}}$ \\
\hline 2.0173 & 0.007 & 2.0170 & 0.008 \\
\hline
\end{tabular}

Notes: The value $\beta$ refers to the estimated long-run coefficient of LY in the model with LL as the dependent variable. SE refers to the standard error. CupBC refers to the continuously updated and bias corrected estimator. CupFM refers to the continuously updated and fully modified estimator. The estimated model includes a constant. 